\title{
EL VISADO COLEGIAL DE PROYECTOS TECNICOS COMO INSTRUMENTO DE DISCIPLINA URBANISTICA
}

357.778.511:71

por

\section{José A. López Pellicer}

Secretario de primera categoría de Administración Local

SUMARIO: I. PLANTEAMIENTO.-II. SIGNIFICACION DEL VISADO: FUNCIONES QUE CUMPLE.-III. NATURALEZA JURIDICA.IV.-SUPUESTOS EN QUE PROCEDE EL VISADO DE PROYECTOS: 1. VISADo de PROYectos POR Colegios de ARouitectos. 2. Visado DE PROYECTOS POR COLEGIOS DE INGENIEROS INDUSTRIALES. 3. VISADO DE PROYeCtOS POR EL COLEgIO DE INGENIEROS DE CAMINOS. 4. VISAdo DE PROYECTOS POR LOS COLEGIOS DE INGENIEROS AGRÓNOMOS.-V. FORMA DEL ACTO DE OTORGAMIENTO O DENEGACION DEL VISADO.-VI. REGIMEN DE IMPUGNACION DEL ACTO DENEGATORIO DEL VISADO: 1. MOTIVOS GENERALES DE IMPUGNACIÓN. 2. IMPUGNACIÓN EN EL ÁMBITO CORPORATIVO. 3. IMPUGNACIÓN EN VIA CONTENCIOSO-ADMINISTRATIVA.

\section{PLANTEAMIENTO}

La situación de indisciplina urbanística que, como señala el preámbulo de la Ley 19/1975, de 2 de mayo, de reforma de la Ley sobre Régimen del Suelo y Ordenación Urbana (LS) caracteriza, entre otros aspectos destacables, la realidad actual del urbanismo en nuestro país, es, como se sabe, uno de los más graves problemas que, a través de la reforma, pretende afrontarse; instrumentando y reforzando para ello una serie de medidas que, por vía 
de control previo, impidan aquella situación, así como el restablecimiento, en su caso, del orden urbanístico cuando sea infringido.

Ante la situación urbanística de que parte, señala paladinamente la Reforma de la Ley del Suelo, entre otras causas determinantes, "la ineficacia de los instrumentos de control»(1). Como es sabido, la efectividad del orden urbanístico - de la Ley del Suelo y sus Reglamentos, en general y del planeamiento urbano, en cada término municipal- se concreta en «el último y definitivo eslabón de la cadena" constituido por la licencia sobre edificación y uso del suelo, tradicionalmente asignada a la competencia municipal. La desconfianza y recelo frente al ejercicio de esta competencia, una de las más típicas y características de las funciones de los $\mathrm{Mu}$ nicipios, no ha llevado al extremo de transferirla y centralizarla en' órganos de la Administración del Estado (2), pero sí a atribuirla a una especie de primera instancia de control corporativo, extramunicipal, a través de los Colegios profesionales, de cuantos proyectos técnicos son necesarios para la ejecución de obras o instalaciones. Se antepone así legalmente, por la reforma de 1975, a la típica licencia municipal de edificación o uso del suelo, la previa fiscalización o control por los Colegios profesionales a quienes corresponde la función de visar los proyectos y trabajos profesionales

(1) Vid. Exposición de Motivos de la Ley 19/1975, de 2 de mayo, apartado II-b. A continuación, la propia Exposición de Motivos, en su apartado $X$, señala que stodo el poderoso arsenal de instrumentos técnicos, económicos y jurídicos a que hasta ahora se ha hecho referencia (se refiere fundamentalmente a los regulados en los órdenes de planeamiento urbanístico y ejecución) puestos al servicio de una concepción del desarrollo urbano que dosifica ya adecuadamente ingredientes de libertad y de intervención, puede resultar absolutamente ineficaz si se rompe el último y definitivo eslabón de la cadena: El de la aplicación efectiva de las Leyes urbanísticas y de los Planes de ordenación. Las innovaciones que contiene el Proyecto se dirigen precisamente a hacer desaparecer en lo posible las causas de aquel fenómeno de indisciplina urbanística que antes se ha analizado y que es preciso corregir. Se trata, sobre todo, de evitar que la infracción se produzca, porque sólo así se evita el coste social que toda infracción comporta. Se procura por todos los medios hacer desaparecer cualquier estímulo al comportamiento antisocial de los presuntos infractores, que pudiera resultar de las insuficiencias del ordenamiento jurídico. Para el supuesto de que, a pesar de todo, se cometa la infracción, todo el peso de la Ley con su secuela de sanciones y responsabilidades debe caer sobre el infractor culpable y, a su sola costa, habrá de prevalecer el interés general.

(2) Tendencia ésta criticada en la doctrina científica. Vid., por todos, J. M. BoOUERA OLIVER: «Licencias contra plan», Revista DE Estudios DE LA VIDA LOCAL, número 172, págs. 578 y ss., y luego también en eLa lucha contra las licencias de edificación viciadas de ilegalidad», en Rev. de Derecho Administrativo y Fiscal, núm. 37 , págs. 8 y ss. 
de los colegiados, al establecer explícitamente el deber de denegar el visado de los proyectos técnicos cuyo contenido infrinja gravemente el orden urbanístico.

El artículo 215 bis de la LS, dice textualmente, en su apartado número tres, que:

«Los Colegios profesionales que tuviesen encomendado el visado de los proyectos técnicos precisos para la obtención de licencias, conforme a lo dispuesto en el artículo 165, denegarán dicho visado a los que contuvieran alguna de las infracciones previstas en el artículo 214, dos»(3).

El visado de proyectos técnicos, aparte de otras funciones que en rigor lo definen conceptualmente, viene a configurarse así, igualmente, como un acto colegial o corporativo de control urbanístico, y el ejercicio de la competencia municipal en materia de intervención y uso del suelo, a través de la clásica licencia, queda en consecuencia mediatizado con la fiscalización previa del proyecto en el aspecto urbanístico por el correspondiente Colegio profesional. La denegación del visado por éste, cuando proceda conforme al nuevo precepto legal citado, excluirá lógicamente la posibilidad de intervención municipal ulterior, al no poder solicitar formalmente el particular interesado la preceptiva licencia, ni la Administración municipal darle curso, ni mucho menos proceder a su otorgamien-

(3) Este precepto, que no figuraba en el proyecto de Ley sobre la Reforma de la LS (publicado en el «B. O. de las Cortes», núm. 1.242, de 5 de diciembre de 1972), es consecuencia de una enmienda presentada in voce por el Procurador señor HeNŔfouez HERnANDEZ. "Con esto -dice- creo que iríamos decididamente, de frente, a que desde el ámbito profesional se pudiera coadyuvar con la Administración. No hablo del caso de una infracción normal o leve, sino del caso de una infracción grave, que son las que contemplamos. Y si de alguna manera hay que coadyuvar, lo veo mejor que sea planteándose seriamente y de un modo general lo que indirectamente pretende el texto, y es que los técnicos no hagan proyectos con infracciones urbanísticas graves, porque cuando se dice que se les va a sancionar es obvio que lo que se pretende es que no se hagan tales proyectos, no que se hagan para sancionarles luego. Con ello se evita el que se fuerce a la Administración a debatir un proyecto cuando éste es objeto de una infracción grave» (Diario de Sesiones de la Comisión de Vivienda de las Cortes, sesión núm. 34, celebrada el día 4 de marzo de 1975, pág. 39); enmienda que la Ponencia estimó a muy sugerente, por cuanto contiene un seguro no solamente dirigido a garantizar prácticamente que ningún proyecto va a incurrir en infracción urbanística, sino que sirve como seguro de los propios técnicos que intervienen en la redacción de los proyectos, puesto que su propio Colegio va a ser el defensor de ellos desde el momento en que les va a advertir de cualquier infracción que pueda contener el proyecton, no obstante el atemor a invadir las facultades de los Colegios al encomendarles con ello funciones que no sean las propias del visado» (página 47). 
to, cuando para ello sea preceptivo acompañar el correspondiente proyecto técnico de la obra o instalación (4).

Indudablemente, esta medida refuerza los instrumentos de control urbanístico al sumarse a la intervención municipal la colegial previa, pero plantea, como vamos a ver, no pocos problemas e inconvenientes.

Aunque la denegación del visado no excluye la competencia municipal, sino la posibilidad de dar curso legal a un proyecto técnico considerado ilegal -por incurrir en infracción urbanística grave-, proyecto que, en consecuencia, deberá ser rectificado para ajustarlo a la normativa urbanística aplicable o sustituido por otro que sea estimado correcto desde el punto de vista urbanístico por el Colegio, en realidad este control colegial preventivo supone el ejercicio por la correspondiente Corporación profesional de una función pública (de policía administrativa) urbanística hasta ahora atribuida exclusivamente a la Administración municipal. En adelante, si bien la competencia para otorgar las licencias de edificación y uso del suelo sigue atribuida formalmente a la competencia del Ayuntamiento (artículo 166 de la Ley del Suelo de 12 de mayo de 1956), sin embargo quedará sustraída materialmente de esta competencia en el supuesto de desestimación del visado de un proyecto cuando, a través del control colegial, se estima que viola gravemente el ordenamiento urbanístico. Sólo podrán, en consecuencia, solicitarse licencias de edificación o uso del suelo conforme a proyectos que hayan sido visados por estimar el Colegio profesional correspondiente que, al menos, no incurren en infracción urbanística grave.

Ahora bien, como la denegación, en su caso, del visado, que formalmente impide solicitar licencia municipal, puede considerarse injustificada por cualquiera de los interesados, arquitecto o cliente, o por ambos, y ello supone cabalmente una limitación de sus derechos o intereses, es obvio que, frente a una posible desestimación del visado que se considere injustificada, y para evitar que aquéllos queden indefensos, resulta necesario establecer un siste-

(4) Cfr. art. 9, núm. 1, primero, del Reglamento de Servicios de las Corporaciones locales de 17 de junio de 1955. Asimismo, la Orden de 9 de mayo de 1940 (cit. infra, en nota 14), y en el mismo sentido, el artículo 8, párrafo 2, de la Orden de 19 de septiembre de 1964 (Ingenieros Industriales) y el artículo 37 de la Orden de 26 de octubre de 1968 (Ingenieros Agrónomos). La sentencia del Tribunal Supremo de 9 de abril de 1970 (Ar. 3.361) dice que la presentación de proyecto, antes de otorgar licencia municipal, es imprescindible. 
ma de garantías jurídicas y, en último término, por tanto, de acciones jurisdiccionales, que cualquiera de aquéllos pueda ejercitar en su defensa, para obtener el visado de un proyecto que se estime que no incurre en infracción urbanística.

El control urbanístico a través del visado obligará asimismo a que los Colegios profesionales establezcan y organicen un servicio administrativo para realizar el cúmulo de funciones que dicho control conlleva, una mínima organización burocrática para llevar a cabo el ejercicio de tales funciones. El conocimiento y aplicación de la legislación urbanística, compleja y variable a nivel de planes y ordenanzas urbanísticas, exigirá a los Colegios disponer de una completa documentación y conocimiento del contenido de estas normas, para que, con referencia a ellas, pueda efectuarse la homologación de todos y cada urro de los proyectos técnicos que sean sometidos al procedente visado. Es fácil imaginar la importancia no sólo cualitativa, según esto, sino también cuantitativa de la labor a desarrollar en este orden, atendiendo al gran número de Municipios a que normalmente alcanza el ámbito de actuación de cada Colegio profesional en su competencia propia y específica.

No son menores, por otra parte, en el estado de la legislación actual relativa a los Colegios profesionales, los problemas que plantea el régimen jurídico de la actuación de estos organismos, pues si bien la Ley de Colegios Profesionales de 13 de febrero de 1974 (LCP) ha tratado de recoger en una disposición de rango legal los principios jurídicos básicos aplicables a los mismos, como ha puesto de relieve la doctrina que se ha ocupado del tema (5), el Derecho aplicable a los Colegios profesionales ofrece una gran diversidad normativa y estatutaria (6) que, a diferencia de lo que ocurre en la Administración del Estado y en la Administración local, supone el mantenimiento, en materia de régimen jurídico de la actuación de cada Colegio (procedimiento y recursos corporativos, especial-

(5) Vid. G. ARIÑo ORTIz: aCorporaciones profesionales y Administración pública», RAP, núm. 72, págs. 27 y ss. Asimismo, BAENA DEL AlCAZAR: "Una primera aproximación a la nueva Ley de Colegios Profesionales», RAP, núm. 74, págs. 55 y ss.

(6) El artículo 6, núm. 1, de la LCP señala que, sin perjuicio de las leyes que regulen la profesión de que se trate, los Colegios profesionales se rigen por sus Estatutos y por los Reglamentos de Régimen Interior. Y concretamente, entre otras materias, serán objeto de regulación mediante los Estatutos generales, el régimen jurídico de los actos y de su impugnación en el ámbito corporativo (artículo 6, núm. 3, apartado h), sin perjuicio de la regulación del funcionamiento de cada Colegio mediante sus Estatutos particulares (art. 6, núm. 4) y Reglamentos de Régimen Interior (art. 6, núm. 1, in fine). 
mente) de la diversidad y dispersión característica de la situación anterior a dicha Ley. Ello obligará, como es lógico, a propósito de nuestro tema, y especialmente en lo que se refiere al supuesto de denegación del visado de un proyecto que se estime injustificada por el particular interesado, a seguir un régimen jurídico diferente, según cada Colegio, que además planteará no pocas dudas y problemas derivados de lagunas e insuficiencias del ordenamiento aplicable en cada caso al visado de proyectos.

No ha de extrañar que, por todo ello, se haya considerado a este respecto, que la preocupación del legislador por las infracciones urbanísticas ha tenido como consecuencia un remedio peor que la enfermedad, que podía haberse solucionado, en forma más acorde con la legislación hasta la fecha vigente, mediante la exigencia a los Colegios de que al visar un proyecto hicieran constar la advertencia de las infracciones urbanísticas que observaren, en relación al mismo, a fin de que el órgano competente para el otorgamiento de la licencia tuviera la obligación de resolver motivadamente y expresamente sobre dichas advertencias, con notificación al Colegio de la resolución que se adoptara a los efectos de recurso (7).

Ahora bien, aun sin desconocer las razones que justifican la anterior postura crítica, es lo cierto, no obstante, que al establecer el nuevo precepto legal una disposición que, en sus propios términos, trasciende de la simple colaboración colegial por vía puramente informativa, para incidir como se verá en el ejercicio de funciones administrativas de carácter resolutorio por los Colegios profesionales afectados, en materia de urbanismo, ni que decir tiene que ello obliga a plantearse el tema del visado bajo este nuevo enfoque jurídico-positivo. Desde este planteamiento, el objeto de nuestro estudio va a consistir fundamentalmente en un aná-

(7) J. M. BusouET: «EI visado como acto de control urbanísticon, comunicación al XLVII Seminario de Investigación organizado por el Instituto de Estudios de Administración Local, sobre régimen jurídico de las licencias de edificación y uso del suelo. Advierte dicho autor que, en la posición extrema que recoge con rango de ley el precepto comentado (art. 215 bis, núm. 3, LS), al ordenar la denegación del visado de los proyectos cuando se contuvieran determinadas infracciones urbanísticas, en la práctica se traspasan las competencias municipales a los Colegios profesionales y se crea un foco de litigio y controversias, que se sustraen al control de la Administración. Destaca asimismo la contradicción del citado precepto legal con los artículos 47-2 y 167 de la Ley del Suelo, que contemplan supuestos que pueden exigir la redacción de proyectos y la solicitud de licencias que no se ajusten al planeamiento vigente y cuyo visado, por tanto, deberán negar los Colegios. 
lisis del régimen jurídico aplicable, en el estado actual de la legislación, a la actividad de otorgamiento o denegación del visado de proyectos, poniendo en conexión el citado precepto de la LS con el ordenamiento aplicable a los Colegios profesionales afectados, tanto a nivel estatutario como general.

\section{SIGNIFICACION DEL VISADO: FUNCIONES QUE CUMPLE}

El visado de proyectos técnicos, en esta nueva perspectiva legal, constituye un acto del Colegio profesional correspondiente, en virtud del cual se constata o comprueba por éste no sólo la conformidad de aquéllos a las normas de la respectiva profesión, sino que determina, asimismo, un control preventivo de su adecuación con la legalidad urbanística.

Como acto de control colegial, el visado cumple esencialmente, por tanto, una doble función:

a) De control de la profesión, y

b) De homologación del contenido del proyecto técnico desde el punto de vista urbanístico.

La función comprobatoria del primer aspecto -el meramente profesional y más propio del visado-, que realiza el Colegio a que el autor del proyecto pertenece, es la función a que tradicionalmente se viene ciñendo su objeto y finalidad, al venir ligada su procedencia y regulada su emisión, a múltiples efectos, así de carácter subjetivo (control de la titulación y colegiación del autor, a fin de evitar el intrusismo en la profesión) como objetivo y formal (comprobación del contenido documental y técnico del proyecto, fundamentalmente), además de otras actuaciones relativamente marginales aunque no menos importantes en la práctica profesional, como son fiscalizar la aplicación de las correspondientes tarifas de honorarios y gestionar su cobro, la distribución equitativa de cargas tributarias entre los colegiados, etc... Pero todos estos aspectos, en sí mismos, no tienen otro alcance que el meramente interno, tanto en el de disciplina de la correspondiente profesión como en el de cumplimiento a través de la organización colegial de una serie de actuaciones y servicios para sus miembros.

La función, por otra parte, que fiscaliza el cumplimiento de la legalidad urbanística, en cuanto determina la procedencia de una 
resolución denegatoria del visado por el respectivo Colegio profesional cuando el proyecto infrinja de modo grave esta normativa, constituye una innovación introducida por la LS (8), pues con anterioridad a esta Ley, la función pública de control urbanístico no correspondía a los Colegios profesionales. En este sentido, por ejemplo, la sentencia del Tribunal Supremo de 4 de mayo de 1974 (Aranzadi 2.290), en su Considerando tercero dice, refiriéndose al alcance del visado, que

«no constituye una garantía de la legalidad del proyecto otorgada por el mencionado Colegio, sino que es sólo una conformidad que se limita a los aspectos meramente técnicos y arquitectónicos de la edificación proyectada» (9).

La rectificación de este tradicional concepto del visado, que limitaba su función a los aspectos puramente profesionales, y la ampliación de su significado y alcance para fiscalizar el cumplimiento de las normas urbanísticas, constituye, pues, una importante innovación introducida por la reforma de 2 de mayo de 1975, para reforzar la instrumentación de la disciplina urbanística previa a la ejecución de las obras o instalación de que se trate, hasta ahora realizada fundamentalmente mediante la clásica y típica licencia municipal de edificación y uso del suelo.

(8) Artículo 215-bis, núm. 3, citado en el texto, en relación con el 214, núm. 2, de la propia Ley de reforma. El control de estas infracciones urbanísticas ha de referirse, por tanto, al bloque normativo integrado por la Ley del Suelo, así como por los planes, programas, normas y ordenanzas, cuya vulneración tendrá la consideración de infracción urbanística (artículo 213), aunque evidentemente la denegación del visado ha de limitarse al supuesto de que la infracción sea calificada de grave.

(9) En el mismo sentido que la sentencia citada en el texto, vid. en la doctrina anterior a la LS, R. MARTfN MATEo: Problemática metropolitana (Estudios y dictámenes), Madrid, Montecorvo, 1974, pág. 33. Asimismo, al comentar dicha sentencia, J. Arozamena: "El ejercicio de la acción pública del artículo 223 de la Ley del Suelo por los Colegios Oficiales de Arquitectos», Rev. de Derecho Urbanístico, número 42, págs. 155-158. Frente a otra línea jurisprudencial que parecía sostener el alcance del visado como acto de control urbanístico colegial (Ss. de 31 de octubre y 25 de noviembre de 1966 y 25 de enero y 7 de junio de 1968), advertía Arozamena que a los Colegios profesionales (de Arquitectos) compete la disciplina de la profesión y no la función pública del urbanismo, en el sentido de que tengan atribuidas competencias urbanísticas, por entender que la denegación del visado cuando el proyecto incumpla la normativa urbanística significaría la invasión colegial de una competencia que corresponde a la Administración municipal en materia de otorgamiento de licencias de edificación (art: 166, núm. 1, de la Ley del Suelo). 
De lo anterior, esto es, de la consideración de que el visado colegial de proyectos técnicos cumple o ha de cumplir una compleja serie de funciones, reconducibles a los dos grandes grupos señalados, no hay que deducir, sin embargo, a nuestro modo de ver, que la LS introduzca un nuevo tipo de visado -el que pudiera denominarse visado urbanístico-, diferente del clásico visado de proyectos, sino que amplía su función para comprender los aspectos urbanísticos. El acto colegial de otorgamiento del visado constituye, según esto, un único acto -a continuación veremos de qué naturaleza - cuyo contenido habrá de comprender en adelante, en su ámbito de control específico, no sólo los aspectos meramente profesionales, sino igualmente los de disciplina en la aplicación del ordenamiento urbanístico, cuya infracción cuando sea grave constituirá, pues, un nuevo motivo o fundamento para desestimar su otorgamiento. Esta concepción unitaria del visado, entendido como un solo acto aunque de contenido complejo atendiendo a las funciones que cumple, se deduce a nuestro juicio de los términos del artículo 215 bis, número 3, de la LS conforme al cual:

a) La nueva función fiscalizadora que en materia urbanística se atribuye a los Colegios profesionales correspondientes hay que situarla y referirla necesariamente al contexto de las normas y estatutos de la respectiva profesión, porque no se establece en dicho precepto que haya de ser realizado el visado por todos los Colegios profesionales respecto de los proyectos elaborados por sus respectivos colegiados, sino únicamente por aquellos Colegios que lo tengan encomendado, extremo este último que hay que interpretar de modo sistemático en relación con lo que establece la LCP de 13 de febrero de 1974, que señala como función específica de los Colegios profesionales, entre otras, la de «visar los trabajos profesionales de los colegiados cuando asi se establezca expresamente en los Estatutos generales» (10).

En virtud de esta remisión o reenvío legislativo, solamente procederá, en consecuencia, el visado de proyectos técnicos cuando se haya establecido de este modo para cada Colegio mediante este tipo de normas estatutarias.

(10) Artículo 5, apartado q), de la Ley de Colegios Profesionales, cit. 
b) Adviértase, a mayor abundamiento, que en el supuesto de que el proyecto técnico incurra en infracción urbanística grave la denegación se refiere al visado como tal, y no a un supuesto visado urbanístico distinto del establecido en los Estatutos generales del respectivo Colegio, a cuyo visado urbanístico pudiera referirse única $\dot{y}$ exclusivamente la función denegatoria, por cuanto la LS establece en tal supuesto que los Colegios profesionales «denegarán dicho visado», esto es, el "que tuviesen encomendado», que, según lo anterior, no puede ser otro que el previsto en su caso en las correspondientes normas estatutarias profesionales de carácter general.

c) Que el visado de proyectos constituye un acto colegial único, si bien comprensivo de diversas funciones de control, lo demuestra el clásico argumento «a contrario», según el cual no quedarán sujetos al deber legal de denegar el visado aquellos Colegios en cuyas respectivas normas profesionales estatutarias no esté establecida o «encomendada» la función de visar los trabajos profesionales de los miembros colegiados.

Así pues, en la hipótesis de que no proceda el visado conforme a los Estatutos generales del Colegio correspondiente, no existirá la posibilidad de que éste ejerza la función de disciplina urbanística que establece el citado precepto de la LS, al venir ligada y conectada legalmente esta función a la procedencia del visado estatutario, por lo que en consecuencia no podrá denegarse por aquél el otorgamiento de un visado que, desde el punto de vista jurídico, no esté comprendido dentro de sus cometidos o funciones propias.

\section{NATURALEZA JURIDICA}

Si, según queda expuesto, el visado de proyectos técnicos cumple una pluralidad de funciones que trascienden del ámbito interno de la profesión, para extenderse en virtud del precepto de la reforma de la LS al control incluso de la adecuación de aquéllos a la normativa urbanística aplicable, mas esta última función no permite diferenciar ni otorgar calificación institucional independiente a un supuesto visado urbanístico, el problema de la naturaleza jurídica habrá que reconducirlo $a b$ initio, en el aspecto 
que aquí nos interesa, al genérico tema de la naturaleza del visado estatutario de proyectos, si bien matizado por la especial circunstancia de comprender en su ámbito el control del cumplimiento por éstos, en cada caso, de la legalidad urbanística aplicable.

Ya en su concepción clásica el visado de proyectos por los Colegios profesionales ha sido calificado de acto jurídico -en razón a que produce efectos de esta índole-y, en concreto, como acto de naturaleza administrativa o acto administrativo (11) por proceder de organismos integrados en el ámbito de la Administración pública (12) y ser emanado en el ejercicio de una potestad conferida y regulada por el ordenamiento administrativo (13); calificación jurídica que viene reforzada además, actualmente y en virtud del precepto de la LS que comentamos; por el ejercicio de la función pública y administrativa que, explícita y directamente, atribuye en materia de urbanismo a las referidas Corporaciones, para el cumplimiento por éstas de fines de interés público, representados en general por la consecución de la denominada disciplina urbanística.

Es indudable que los actos emanados por los Colegios profesionales en el ejercicio de esta potestad-función, afectarán no sólo a los intereses públicos, sino también a particulares, tanto a los colegiados (no ya como miembros corporativos, sino como titula-

(11) Vidi, en la doctrina más reciente, E. GARcta DE ENTERRta: Curso de Derecho Administrativo, I, Madrid, 1974, pág. 235, donde cita concretamente el visado de proyectos técnicos como ejemplo de ejercicio por los Colegios profesionales de facultades en el orden administrativo.

(12) Los Colegios profesionales, en cuanto Corporaciones de Derecho público (art. 1, núm. 1, de la LCP de 13-II-1974), sometidas a la tutela del Estado, se califi. can legalmente de Administración pública, especialmente a efectos administrativos y contenciosos (art. 1, núm. 2, apartado c, de la Ley 27-XII-1956, reguladora de la Jurisdicción contencioso-administrativa). ARIÑo ORTIZ precisa que la idea de tutela no ha de entenderse como encuadramiento de las Corporaciones profesionales en la organización estatal, ya que se trata - dice- de "personas públicas no estatales», que "se encuentran fuera del Estadon, excepto cuando ejercen facultades delegadas del Estado, en cuyo caso se produce una reintegración a éste por vía jerárquica.

(13) La potestad para ejercer la función del visado se atribuye directamente a los Colegios profesionales por la citada LCP de 13-II-1974 (art. 5-q, cit.), aunque, como queda indicado, se condiciona legalmente su exigencia a que así esté previsto de modo explícito en los Estatutos generales del respectivo Colegio. Comentando la citada Ley, advierte BAENA DEL ALCÁzAR que, aunque no todas las funciones que ejercen dichos Colegios son actos administrativos, si lo son aquellas que desarrollen en el ejercicio de una competencia pública o potestad administrativa y cuyo ejercicio esté regulado en consecuencia por el ordenamiento administrativo (estudio citado en nota 5, págs. 86 y 105). En análogo sentido, a este respecto, ARIÑo OrIIZ, en el estudio citado en la misma nota 5, págs. 99 y ss. 
dos particulares que ejercen una determinada profesión), como a los clientes que a ellos acuden en demanda de que les sea elaborado un proyecto que ha de constituir la base técnica para realizar una determinada obra o utilización del suelo; particulares cuyos derechos o intereses legítimos pueden verse limitados, cuando no denegados en su concreto ejercicio, en el caso de que el visado se desestime, sin posibilidad en este supuesto de que el proyecto técnico sea admitido por la Administración o Ayuntamiento competente para otorgar la correspondiente autorización de obras o de utilización del suelo (14).

Partiendo de la naturaleza de acto administrativo que cabalmente hay que atribuir, según lo dicho, al acto de otorgamiento o, en su caso, de denegación del visado de proyectos técnicos por los Colegios profesionales, preciso es proceder a su calificación, dentro de la doctrina general del acto administrativo, atendiendo a los principales aspectos (subjetivo, objetivo y formal) que constituyen y tipifican concretamente este tipo de actuación administrativa.

a) A los Colegios profesionales que tienen encomendado el visado de proyectos técnicos se les atribuye directamente por la LS la competencia para verificar el control urbanístico del contenido de aquéllos, aunque sin perjuicio, como es lógico, de la posterior intervención que compete realizar a otras Administraciones públicas y en especial a la Administración municipal (artículo 166 de la LS). Esta intervención municipal posterior se verá mediatizada, no obstante; por el juicio que al respectivo Colegio profesional merezca el proyecto técnico desde el punto de vista normativourbanístico.

Ahora bien, aunque no se produce legalmente una exclusión de la competencia municipal para otorgar o denegar en su caso la licencia correspondiente, sí se produce en el fondo con ello una sustitución previa del juicio que corresponde emitir al Ayuntamiento, especialmente cuando por el Colegio se deniegue el otorgamien-

(14) El visado de proyectos de obras será requisito indispensable para la tramitación de aquéllos por los Municipios respectivos y condición también previa e inexcusable para ser autorizada la realización de las obras proyectadas, según determina el artículo primero de la Orden de 9 de mayo de 1940 y recuerda J. ARozAMENA en el estudio citado en la nota 9, pág. 156. Vid. asimismo las disposiciones citadas en nota 4. 
to del visado, ya que en este supuesto el Ayuntamiento no podrá formalmente conocer de la petición del particular interesado, al verse obligada la Administración municipal a rechazar o no admitir el proyecto técnico que se presente sin el preceptivo visado colegial.

No hay, pues, propiamente, actuación competencial concurrente en el control de la legalidad urbanística entre el Colegio profesional y el Ayuntamiento, sino sucesión de controles preventivos, de los que el primero, por vía colegial, viene a sustituir materialmente, al recaer sobre el mismo objeto, al que compete realizar al Ayuntamiento para otorgar la licencia. A la competencia municipal se sobrepone, pues, la del Colegio correspondiente, actuándose de esta manera un complejo de competencias superpuestas en materia de policía administrativa urbanística.

La depuración previa por el correspondiente Colegio de los vicios que se aprecien en el proyecto desde el punto de vista urbanístico, determina que, salvo error en la calificación de la infracción urbanística o visado otorgado de modo improcedente, la posterior intervención municipal por vía de licencia de obras, etc., quede limitada lógicamente a los supuestos de obras o usos solicitados conforme a proyectos técnicos que en lo esencial cumplan la legalidad urbanística y que, en consecuencia, deberán ser normalmente autorizados, habida cuenta del carácter reglado que tiene la actuación municipal en la materia.

b) En el aspecto objetivo, puede ser caracterizado el visado como un acto de comprobación y de carácter reglado, ya que el Colegio ha de limitarse en su actuación a constatar si el proyecto técnico cumple o no la normativa urbanística, viniendo en consecuencia obligado a otorgar o denegar su otorgamiento según proceda. No hay actuación discrecional de los Colegios profesionales en esta materia, sino simple confrontación del proyecto con las normas urbanísticas aplicables, para concluir en definitiva sobre la procedencia de su otorgamiento, cuando se advierta su conformidad con ellas, o, por el contrario, su denegación en el supuesto de que su contenido incurra en infracción urbanística.

Ahora bien, según los términos del artículo 215 bis, número 3, de la LS -que hay que interpretar en sentido estricto, por tratarse de una norma de carácter limitativo-, en el caso de que 
el contenido del proyecto no cumpla la legalidad urbanística, el visado, como acto de comprobación colegial, tendrá distintas consecuencias en el orden resolutorio según que la infracción advertida sea calificada de leve o grave, ya que sólo en este último caso determinará el deber para el Colegio profesional de denegar el visado, pero no en cualquier otra hipótesis, aunque se trate de infracciones urbanísticas de carácter leve, en cuyo caso el visado no podrá, en consecuencia, ser denegado.

Lo anterior no obsta, en cualquier caso, el ejercicio de la competencia municipal, una vez otorgado el visado, para fiscalizar la adecuación del proyecto a las normas urbanísticas aplicables, a través del correspondiente procedimiento de licencia. No hay que excluir cabalmente, por ello, la hipótesis de un proyecto que haya sido visado favorablemente $\mathrm{y}$, sin embargo, la Administración municipal advierta después la existencia de infracciones graves no advertidas o que hayan sido calificadas simplemente como leves en la fiscalización colegial previa.

c) En el aspecto formal, en fin, se plantea la cuestión de calificar el acto de otorgamiento o de desestimación del visado como un simple acto de información o consulta o como acto resolutorio (15). Nos pronunciamos por esta última tesis, en razón a què, como se verá después con más detalle, el visado constituye una manifestación externa y jurídica de la voluntad corporativa, que se integra a través de un procedimiento administrativo cuyo acto final será su otorgamiento o, en su caso, denegación, con efectos inmediatos para los derechos e intereses de los particulares afectados.

Que no se trata, a nuestro modo de ver, de un simple acto de trámite, informe o consulta, sino de un acto resolutorio, lo demuestra :

1.․ La circunstancia, por un lado, de que el citado precepto de la LS no se limita a exigir, en el supuesto de que se adviertan en el proyecto infracciones de carácter grave, que éstas se expresen en el visado, lo que sí significaría atribuirle a efectos urbanísticos un valor de simple informe, sino que va mucho más allá

(15) Sobre la distinción formal entre actos resolutorios y actos de trámite, vid. en general J. GonzAlez PÉrez: El procedimiento administrativo, Madrid, 1964, páginas 301 y siguientes. 
al establecer de modo imperativo que, en tal hipótesis, deberá denegarse por el Colegio su otorgamiento.

2.․ Asimismo, la trascendencia jurídica que para el particular o particulares interesados tiene la denegación del visado, que formalmente determina la imposibilidad de solicitar licencia municipal, por cuanto aquél no podrá acompañar a su petición de licencia el preceptivo proyecto técnico con el correspondiente visado -cuando éste sea preceptivo- ni en este supuesto podrá verificarse su admisión a trámite por la Administración municipal, según queda indicado (notas 4 y 14).

No sólo la configuración del supuesto legal a que nos referimos, sino también las consecuencias de la actuación colegial, sobre todo cuando ésta sea desestimatoria del visado, nos ponen de manifiesto que se trata de un acto administrativo que tiene carácter resolutorio o final de un procedimiento administrativo tramitado en el ámbito de la respectiva Corporación profesional; cuyo acto condiciona legalmente la incoación de otro procedimiento posterior, ante una segunda instancia administrativa o municipal, respecto de la cual el visado tiene, por tanto, carácter inicial o previo.

\section{SUPUESTOS EN QUE PROCEDE EL VISADO DE PRO- YECTOS}

El reenvío que la LCP hace a los Estatutos generales de cada organización colegial (16) obliga a un casuístico examen para determinar los supuestos en que procede el visado, ya que a ello se conecta legalmente, en el aspecto que específicamente interesa destacar ahora, la disciplina urbanística de los proyectos técnicos por los Colegios profesionales, al venir atribuida esta función solamente a los Colegios "que tuvieren encomendado el visado".

Por su mayor interés teórico y práctico, vamos a examinar en especial los supuestos de visado de proyectos técnicos según las normas o estatutos de los Colegios profesionales de Arquitectos,

(16) Cfr. art. 5, apartado q), cit. supra. Se excluyen, a contrario sensu, los Estatutos particulares de cada Colegio y los Reglamentos de Régimen Interior, al referirse explícitamente la LCP en dicho precepto a los Estatutos generales, elaborados por el respectivo Consejo General de Colegios (art. 9-1-b), y cuya aprobación compete al Gobierno (art. 6-2). 
Ingenieros Industriales, Ingenieros de Caminos e Ingenieros Agrónomos. Aprobados todos ellos con anterioridad a la LCP de 13 de febrero de 1974, sólo los Estatutos de los Colegios de Arquitectos han sido aprobados por Decreto (17); los demás lo han sido por Ordenes ministeriales (18) y concretamente en el caso de los Ingenieros de Caminos las normas sobre el visado están contenidas en el Reglamento de Régimen Interior del Colegio. En atención al rango y naturaleza de este tipo de normas, se plantea el problema de si procede la exigencia del visado cuando no esté establecido expresamente en los Estatutos generales del Colegio, sino en normas estatutarias particulares o de régimen interior. En cualquier caso, nos pronunciamos en principio sobre la procedencia del visado, en cualquiera de estos casos, sin perjuicio de la adaptación de la forma de su régimen a lo que dispone la LCP (19).

Veamos los supuestos más frecuentes y normales de proyectos técnicos para los que está previsto actualmente el visado por el correspondiente Colegio profesional.

\section{Visado de pRoyectos por Colegios de ARQuitectos}

El artículo 3. ${ }^{\circ}$ de los Estatutos generales, aprobados por Decreto de 13 de junio de 1931, establece que el objeto fundamental de los Colegios será procurar que se cumplan en todos los casos los fines que corresponden a la arquitectura considerada como una función social, y de modo especial, entre otros fines, determina que

(17) Decreto de 13 de junio de 1931 (Diccionario de Legislación Aranzadi, número marginal 3.843).

(18) O. del Ministerio de Industria de 19 de septiembre de 1964 (Colegio de Ingenieros Industriales), O. del Ministerio de Obras Públicas de 21 de mayo de 1959 (C. de Ingenieros de Caminos), y O. del Ministerio de Agricultura de 26 de octubre de 1968 (C. de Ingenieros Agrónomos).

(19) La disposición transitoria primera de la LCP establece que alas disposiciones reguladoras de los Colegios Profesionales y de sus Consejos Superiores y los Estatutos de los mismos continuarán vigentes en todo lo que no se oponga a lo dispuesto en la presente Ley, sin perjuicio de que se puedan proponer o acordar las adaptaciones estatutarias precisas, conforme a lo dispuesto en la misman. Vid. BaEna del Alcázar, estudio citado en nota 5, pág. 79. Advierte BaEna que la citada disposición transitoria no formula ningún mandato, sino que simplemente permite ( $\alpha$ sin perjuicio de que se puedan...») acordar o proponer las adaptaciones estatutarias precisas; pero, aunque esto es así, a nuestro juicio, en los casos en que el régimen de visado de proyectos no sea conforme con lo que dispone dicha Ley, para evitar problemas y dudas en lo que se refiere a su vigencia, se impone la inclusión de su normativa en normas estatutarias con rango adecuado. 
les corresponde hacer cumplir las normas a que debe sujetarse la actuación profesional, tanto en la formación de proyectos como en la dirección de las obras, así como también en la esfera pericial (apartado $\mathrm{j}$ ).

En cuanto a la procedencia del visado, el artículo 15 de los citados Estatutos dispone que «todos los proyectos y documentos periciales formulados por los colegiales tendrán que ser presentados al Colegio en la forma que determine el Reglamento correspondiente. Estos trabajos serán sellados y aprobados por el Colegio, en el que se llevará un registro de los mismos».

La competencia orgánica para el visado se atribuye específicamente a la Junta de Gobierno del respectivo Colegio. El artículo 19 de los Estatutos generales establece que corresponde de modo especial a las Juntas de Gobierno, con relación a los colegiados: «...d) Intervenir para su validez la documentación de los proyectos y direcciones de obras que hayan de tener curso alministrativo por medio del sello del Colegio y visar de igual modo todos los informes de carácter privado, periciales, valoraciones, etc., los cuales deberán quedar registrados en el Colegio».

El Estatuto general de los Colegios de Arquitectos establece, pues, de modo expreso la procedencia del visado, aunque no la forma como ha de realizarse esta actuación, que será la que determine el Reglamento de cada Colegio. Así, por ejemplo, el Reglamento orgánico número 4 del Colegio de Madrid, sobre actuación profesional y control, establece la forma de llevar a cabo este control, a cuyo efecto constituye Comisiones de Control -cuya composición asimismo regula- en cada una de las capitales de Provincia que constituyen el Colegio, bajo la inspección de la Junta de Gobierno (artículo 2), regulando a continuación, en su artículo 8, el procedimiento de actuación de estos órganos para otorgar el visado correspondiente o denegarlo cuando exista causa justificada, en la forma siguiente:

«El Vocal o Vocales de turno que ejerzan la función del visado y registro podrán reservarse el derecho de no sellar todos o algunos de los documentos presentados, en cuyo caso extenderá la oportuna acta en el libro registro, de la que dará copia firmada al Arquitecto interesado, haciendo constar en ambas las causas que motivaron la decisión y contraseñando con su rúbrica los documentos excluidos. 
El Pleno de la Comisión deberá reunirse en un plazo de tres días, y después de oír al interesado y examinar los documentos excluidos, decidirá, en ausencia de aquél, si procede ratificar o enmendar la actitud del Vocal denegador. De todo lo actuado se levantará acta por el Vocal más moderno, actuando de Secretario, y con exclusión del denegador, que será elevada a conocimiento de la Junta de Gobierno, la que resolverá en un plazo de cinco días en caso de denegación del sellado por la Comisión, pasando el expediente a la Comisión de depuración profesional, si considera haber lugar a ello.

Serán causas de denegación del visado: las faltas patentes de decoro en la presentación de documentos; el incumplimiento de los Reglamentos a que se refiere el artículo tercero, apartados $\mathrm{j}$ ) y k), de los Estatutos del Colegio; la falta de sujeción a las condiciones especificadas en el contrato celebrado entre el Arquitecto y el cliente, y la no presentación de alguno de los documentos que se enumeran en el artículo 10.

Para el más exacto cumplimiento de lo anteriormente expuesto existirá en cada una de las Comisiones, a disposición de los colegiales, una recopilación legislativa y normativa, quedando obligado el Colegio a comunicar a sus miembros cuantas disposiciones se dicten con carácter obligatorio.

En los casos de visado bajo reserva, el Vocal actuante pondrá en conocimiento de la Comisión el caso, para que resuelva en un plazo de cinco días. Si lo estimara oportuno la Comisión, dará conocimiento inmediato a la Junta de Gobierno, la cual decidirá en un plazo de ocho días o elevará el expediente a la Comisión de depuración profesional.

El Arquitecto interesado tendrá siempre derecho de apelación ante la Junta de Gobierno si estimase lesionado su derecho por el Vocal actuante o la Comisión de Control, sin perjuicio de lo que dispone el Reglamento de la Comisión de depuración profesional.

A los efectos de las decisiones que adopten las Comisiones de Control, la Junta de Gobierno y la Comisión de depuración profesional, servirán de pruebas los documentos sometidos al visado, ya estén sellados por considerarse aprobados, o contraseñados en el caso de exclusión». 


\section{VisAdo DE PROYECTOS POR COLEgios de INGENIERos INDUSTRIALES}

Aunque a efectos de la percepción del 10 por 100 de los honorarios de los colegiados como recurso económico ordinario del correspondiente Colegio, la Orden del Ministerio de Industria de 19 de septiembre de 1964 que modifica los Estatutos de los Colegios de Ingenieros Industriales, impone expresamente la obligatoriedad del visado de los proyectos técnicos, al establecer que "los Ingenieros Industriales procedentes de las Escuelas Técnicas Superiores creadas por el Estado o que en lo sucesivo se creen por el mismo que, en cumplimiento de lo establecido en el artículo único del Decreto 1533/1964, de 14 de mayo, estén obligados a pertenecer al Colegio habrán de someter a visado y registro la documentación de carácter profesional que debe presentarse en las dependencias del Estado, Provincia o Municipio u otros organismos de carácter oficial. Dicho visado y registro deberá efectuarse en el Colegio en cuyo ámbito territorial radique o vaya a radicar la industria, instalación o servicio y, en general, aquello que sea objeto de dicha documentación. El incumplimiento de tal requisito invalida esta documentación a los efectos de su presentación con carácter oficial en aquellas dependencias que, en consecuencia, no deberán admitirla».

El Decreto de 24 de julio de 1969 establece asimismo que no se admitirá en ninguna dependencia ni organismo del Estado, Corporaciones locales, Organización Sindical, Institutos oficiales de Crédito ni en cualquiera otra Entidad estatal autónoma o no, proyectos de trabajos técnicos o facultativos de ingeniería industrial, cuya firma requiera el título de Ingeniero Industrial realizados en beneficio de entidades o personas físicas privadas si no están visados por el Colegio de Ingenieros Industriales correspondiente (artículo 7, núm. 2) (20).

(20) Este último Decreto prevé en su disposición transitoria primera la redacción de unos nuevos Estatutos generales, y en su disposición transitoria segunda, que hasta que los mismos se aprueben quedarán subsistentes, en lo que no se opongan a dicho Decreto, los aprobados por O. M. de 6 de septiembre de 1950, con las modificaciones introducidas por las O. M. de 21 de marzo de 1959 y 19 de septiembre de 1964. 
3. Visado de proyectos por el Colegio de Ingenieros de $\mathrm{CA}_{\text {- }}$ MINOS

Será necesario el visado del Colegio —establece el artículo 60 del Reglamento de Régimen Interior aprobado por Orden de 21 de mayo de 1969 - para acreditar que el Ingeniero de Caminos, Canales y Puertos firmante de un trabajo o proyecto cumple las condiciones señaladas en el artículo 11 de los Estatutos generales, salvo los correspondientes al primer caso del artículo 55 de este Reglamento (salvedad que se refiere a los servicios profesionales prestados por colegiados que actúan como funcionarios públicos en el ejercicio de los deberes de sus cargos).

El visado de documentos se efectuará en la sede del Colegio; pero esta función podrá transferirse a alguna o a todas las Delegaciones si así lo acuerda el Consejo de Administración y con sujeción a las normas que éste fije (artículo 64).

El visado de documentos, comprobando y haciendo cumplir las normas establecidas, corresponde a la Comisión de Inspección de! Colegio, aunque existe una Delegación Permanente encargada de la tramitación normal de los asuntos (21).

\section{Visado de pRoyectos por los Colegios de Ingenieros Agró- NOMOS}

El artículo 6, apartado j), de los Estatutos generales prevé expresamente como función de los Colegios de Ingenieros Agrónomos la de "visar los trabajos profesionales una vez comprobado que se ajustan a las normas establecidas".

La exigencia del visado está establecida además como requisito necesario para la tramitación ante cualquier Administración pública de cualquier trabajo profesional realizado por los Ingenieros Agrónomos para clientes particulares. Los Estatutos generales, tras

(21) El artículo 65, núm. 1, del citado Reglamento establece que habrá una Comisión de Inspección, presidida por el Consejero de más edad y miembros de la misma, constituida por cuatro Consejeros renovables anualmente y elegidos por el Consejo de Administración en sesión ordinaria, a propuesta del Presidente del Colegio, por el Director y por el Secretario de Organización. La Delegación Permanente, encargada de la tramitación normal de los asuntos, estará constituida por el Director y el Secretario de Organización. 
señalar que corresponde al Colegio el visado de trabajos profesionales en el caso de que hayan sido realizados con la colaboración o ayuda de Peritos agrícolas (artículo 36), establece expresamente que en ninguna dependencia del Ministerio de Agricultura se admitirán ni tramitarán trabajos técnicos o facultativos de cualquier clase, realizados en beneficio del interés privado y para cuya firma se requiera el título de Ingeniero Agrónomo, si no están visados por alguno de los Colegios de Ingenieros Agrónomos. Las mismas normas deberán aplicarse por los restantes organismos oficiales del Estado, Provincia, Municipio, Organización Sindical y Corporaciones y Tribunales de cualquier orden y jurisdicción cuando se presenten tales trabajos suscritos por Ingenieros Agrónomos (artículo 37).

\section{FORMA DEL ACTO DE OTORGAMIENTO O DENEGACION DEL VISADO}

La actual normativa de los Colegios profesionales con competencia para el visado de proyectos técnicos suele remitir, expresa o tácitamente, la regulación del procedimiento y forma como ha de realizarse la actuación administrativa colegial a lo que determine el Reglamento de régimen interior de cada Colegio. Así ocurre, por ejemplo, en el caso de los Colegios de Arquitectos, cuyos Estatutos generales, según hemos visto, remiten expresamente al Reglamento de cada Colegio la forma de presentación de los proyectos a los efectos del correspondiente visado (artículo 15) y en el caso del visado de proyectos elaborados por Ingenieros de $\mathrm{Ca}$ minos, cuya forma de presentación y trámite corporativo regula el Reglamento de Régimen Interior de 21 de mayo de 1959 (22),

(22) En su artículo 67 establece que alos documentos que deban someterse al visado se presentarán por duplicado en cualquiera de las Delegaciones regionales y se canjearán por un resguardo de entrega, en el que se hará constar la fecha de presentación y la del día en que pueda ser recogida una de las series presentadas, quedando la otra archivada en el Colegio» (párrafo 1). aLas Delegaciones remitirán los documentos y sus respectivas relaciones a la Comisión de Inspección para que en su caso se proceda al visado, estampando un sello fechado en cada uno de los documentos» (párrafo 5).

aLos documentos presentados al visado serán sometidos al examen de la Delegación Permanente, que actuará todos los días hábiles para el Colegio. Esta, cuando no tenga duda de que los documentos están en regla, procederá al visado, pudiéndose poner previamente de acuerdo con los colegiados para efectuar alguna rectificación, si se estima procedente. En los casos dudosos o cuando juzgue que se 
sin que las normas profesionales de los Colegios de Ingenieros Industriales y de Ingenieros Agrónomos contengan una expresa ordenación de la forma como ha de otorgarse o denegarse el visado.

La cuestión no es ni mucho menos baladí si tenemos en cuenta que el procedimiento del visado, como todo procedimiento administrativo, constituye no sólo elemento formal de la actuación corporativa, sino sobre todo en el caso de denegación por razones urbanísticas, por afectar al régimen de garantías jurídicas de los particulares afectados. No creemos, por ello, que esta importante materia pueda dejarse, en cuanto a su regulación, a los Reglamentos de régimen interior de cada Colegio. Se impone una revisión de la anterior normativa en este aspecto, como en otros, en cuanto debe ser objeto de regulación en los Estatutos generales de cada Colegio, el régimen jurídico de los actos y de su impugnación en el ámbito corporativo (artículo 6 , número 3 , apartado $h, L C P$ ) e incluso la forma de aprobación de las actas, estableciendo el procedimiento de autenticidad y agilidad para la inmediata ejecución de los acuerdos (apartado i del propio precepto legal). Con ello se logrará cuando menos unificar en el ámbito de cada profesión «técnica» el procedimiento de actuación administrativa $\mathrm{y}$, en consecuencia, de otorgamiento o denegación del visado, aunque evidentemente esta adaptación a la LCP no impedirá la existencia de una gran diversidad en la regulación del procedimiento y forma de actuación de cada Colegio (23), quebrando por completo la unidad

debe negar el visado, someterá el asunto al Pleno de la Comisión para su resolución. Contra los acuerdos denegatorios (de la Comisión de Inspección, en Pleno) los colegiados podrán recurrir ante el Consejo de Administración en un plazo de quince días, a partir de la fecha de notificación del acuerdos (art. 70).

Para examinar la actuación de la Delegación Permanente, la Comisión de Inspección celebrará sesión ordinaria una vez al mes, excepto en agosto (art. 71, nú. mero 1), regulándose a continuación el quórum de constitución de la Comisión (núm. 2) y la forma de adoptar los acuerdos denegatorios, así como la posibilidad de efectuarse un "visado bajo reserva, siempre que el colegiado se obligue a cumplir las prescripciones que dicte la Comisión de Inspección, dentro del plazo que se le fije, considerándose como falta grave el incumplimiento de esta obligación» (art. 72).

«El visado de documentos se efectuará mediante un sello y significará que cumplen los requisitos mínimos formales establecidos en las normas vigentes, sin que por lo tanto el Colegio se haga responsable de la redacción de los mismos ni de que su autor infrinja al firmarlos alguna obligación de tipo legaln (art. 73).

(23) Advierte BAENA DEL AlĆ́zAR, en este sentido, al estudiar los problemas que plantea el régimen jurídico de los actos de los Colegios profesionales, que "parece ser pretensión de la Ley (de 13 de febrero de 1974) que cada uno de los Estatutos generales contenga una regulación específica del procediminto administrativo de cada Colegio, lo que supondrá quizá la más extraordinaria dispersión» (Estudio citado en nota $5, R A P$, núm. 74 , pág. 83 ). 
que intentó instaurar la Ley de Procedimiento administrativo de 17 de julio de 1958, ya que esta Ley no se aplica a los Colegios profesionales como Derecho supletorio (24).

No obstante, según se desprende de la normativa estatutaria reguladora de los Colegios profesionales a que se ha hecho mención con anterioridad, el otorgamiento del visado $y$, con mayor motivo, su denegación, deben resolverse por el correspondiente órgano colegial mediante forma expresa (25). Aunque el acto de otorgamiento del visado se traduzca materialmente, según las respectivas normas estatutarias y de régimen interior, en el hecho de sellar el proyecto y documentos sometidos a la función fiscalizadora colegial, la denegación, por cualquier causa, y también por razones urbanísticas, en el supuesto del artículo 215 bis, número 3, de la LS, no puede entenderse simplemente, a nuestro juicio, en el sentido de no sellar materialmente el proyecto técnico, ya que esta actuación material sólo será reflejo y aplicación de una actividad jurídica previa, que deberá expresar los motivos o fundamentos jurídicos de la resolución denegatoria, que por lo demás deberá ser notificada a los interesados - técnico y cliente, normalmentecon advertencia de los recursos administrativos o "corporativos»: y jurisdiccionales legalmente procedentes frente al acto colegial desestimatorio.

En apoyo de esta interpretación, cabe citar las siguientes razones:

Primera.-La naturaleza jurídica y administrativa del acto de denegación del visado de proyectos técnicos por razones urbanísticas, en cuanto supone ejercicio por los correspondientes Colegios profesionales de una función pública en materia de urbanismo, que les viene atribuida directa y expresamente por la LS, y cuya regulación está contenida en normas jurídicas de carácter administrativo.

Segunda.-Las normas reglamentarias de los Colegios profesionales que tienen encomendado el visado de proyectos (así, en el caso de los Colegios de Arquitectos y de Ingenieros de Caminos), en lo que se refiere concretamente al procedimiento de actuación,

(24) Vid. BaENa DEL Alcazar, estudio citado en nota 5, RAP, núm. 74, pág. 84. Asimismo, ARIÑo OrTIz, estudio citado en la misma nota, $R A P$, núm. 72, págs. 43 y 69.

(25) En cuanto al silencio administrativo, será aplicable el régimen de la LJCA de 27 de diciembre de 1956 (arts. 38 y 54), aplicable a los Colegios profesionales en cuanto Corporaciones de Derecho público (art. 1). 
establecen que la denegación del visado ha de hacerse mediante resolución o acuerdo del correspondiente órgano colegial (26).

Tercera.-La necesidad de determinar expresamente las causas que, en su caso, motivan la denegación del visado, que en el supuesto a que especialmente nos referimos, serán las de contener el proyecto técnico alguna infracción urbanística de carácter grave (27), a fin de que por el interesado - Arquitecto, cliente- puedan ejercerse los recursos administrativos y jurisdiccionales procedentes, como garantía de sus derechos (28).

Cuarta.-El acto administrativo denegatorio deberá ser objeto de notificación a los interesados, para que por éstos puedan ejercerse los anteriores recursos. En el supuesto de que se denegase la simple operación material de sellar un proyecto sin acto jurídico o título - resolución o acuerdo- que le sirva de fundamento, habrá que aplicar, por ello, el régimen de silencio administrativo que establecen los artículos 38 y 54 de la Ley de 27 de diciembre de 1956, reguladora de la jurisdicción contencioso-administrativa (según se actúe en vía de petición o en vía de recurso, respectivamente), para salvaguardar en cualquier caso las garantías jurídicas de los particulares o entidades afectadas por la denegación, en el orden jurisdiccional.

\section{REGIMEN DE IMPUGNACION DEL ACTO DENEGATORIO DEL VISADO}

La configuración de la actividad de control urbanístico por los Colegios profesionales, a través del visado de proyectos técnicos, como función pública atribuida a estos organismos o entidades de

(26) Cfr. artículo 8 del Reglamento Orgánico del Colegio de Arquitectos de Madrid, aplicable a la actuación profesional y a su control, citado en el texto, supra, y los artícutos 70 a 72 del Reglamento del Colegio de Ingenieros de Caminos, asimismo citados con anterioridad (nota 22).

(27) Si han de expresarse las causas de denegación del visado cuando éste es entendido como simple acto de control y disciplina de la profesión (vid. artículo 8, párrafo 3, del Reglamento del Colegio de Arquitectos citado en la nota anterior), con mayor razón ha de hacerse cuando trasciende de este ámbito interno y afecta a la función pública del urbanismo como sucede en el supuesto de denegación por razones de esta naturaleza.

(28) El artículo 8 de la LCP establece que alos actos emanados de los órganos de los Colegios y de los Consejos Generales, en cuanto estén sujetos al Derecho Administrativo, una vez agotados los recursos corporativos, serán directamente recurribles ante la Jurisdicción Contencioso-administrativas (apartado 1). Al régimen de impugnación del acto denegatorio del visado nos referimos con mayor detalle infra. 
la llamada Administración corporativa, función o potestad en cuyo ejercicio emanan, por tanto, auténticos actos administrativos, actos de poder público, determina y obliga, como contrapartida, a establecer un sistema de defensas jurídicas frente a tales actos, y en particular como es lógico en el supuesto denegatorio, tanto en el ámbito administrativo como en el orden jurisdiccional, mediante la impugnabilidad del acto de desestimación del visado que se considere no conforme a Derecho (así, cuando por ejemplo, se entienda que el proyecto no infringe el ordenamiento urbanístico $o$, al menos, no lo hace de modo grave), primero en vía administrativa, ante el propio Colegio u organismo de la Administración con facultades de tutela sobre el mismo, en su caso, y en último término ante la jurisdicción contencioso-administrativa conforme a lo que determina la Ley de 27 de diciembre de 1956, reguladora de esta jurisdicción.

El régimen de impugnación del acto colegial denegatorio del visado de un proyecto, en cuanto acto de naturaleza administrativa, ha de analizarse dentro del cuadro o esquema general de los recursos y garantías jurídicas frente a las actuaciones de la Administración pública, puesto que, dentro de ésta, se encuadran legalmente los Colegios profesionales (artículo 1, núm. 2, apartado c, de la citada Ley Jurisdiccional). Si el tema objeto de nuestro estudio no planteara especiales problemas, bastaría con que nos remitiéramos al régimen general de impugnación de los actos administrativos, pero las cuestiones que suscita la diversidad de normas estatutarias y reglamentarias específicas de cada Colegio, por un lado, y la circunstancia, por otro de trascender las consecuencias del acto desestimatorio del visado del ámbito "corporativo", interno, del respectivo Colegio, al limitar de modo unilateral el ejercicio de derechos $o$ intereses de terceras personas - los clientes-, obliga a plantearse, dentro del esquema general de garantías jurídicas frente a la actuación administrativa, las particularidades más destacables del régimen impugnatorio del tipo de acto que consideramos.

\section{Motrvos GENERALES DE IMPUGNACION}

La LCP contiene, a este respecto, una ordenación expresa del régimen general de la nulidad y anulabilidad de los actos administrativos de los órganos colegiales, que han de servir, en su caso, 
como motivos en que podrá fundarse la impugnación de tales actos. Según el artículo 8, número 3, de la citada Ley, son nulos de pleno derecho los actos de los órganos colegiales en que se den algunos de los siguientes supuestos: Los manifiestamente contrarios a la Ley; los adoptados con notoria incompetencia; aquellos cuyo contenido sea imposible o sean constitutivos de delito; los dictados prescindiendo total y absolutamente del procedimiento legalmente establecido para ello o de las normas que contienen las reglas esenciales para la formación de la voluntad de los órganos colegiados.

Son anulables - añade el mismo precepto legal - los actos que incurran en cualquier infracción del ordenamiento jurídico, incluso la desviación de poder.

No vamos a reiterar aquí, por haber sido analizada por la más calificada doctrina administrativista y para no incurrir en innecesarias repeticiones, el estudio de estos supuestos generales de invalidez de los actos administrativos (29), ya que, como fácilmente se advierte, el citado precepto legal sigue en términos generales el modelo de los artículo 47 y 48 de la Ley de Procedimiento administrativo de 17 de julio de 1958, aunque, como diferencia, aquél precepto de la LCP amplía los supuestos de nulidad absoluta con el de los actos manifiestamente contrarios a la Ley y modifica, por otro lado, la causa de nulidad por incompetencia (30).

(29) Vid., en general, por todos, J. A. Santamarfa Pastor: La nulidad de pleno derecho de los actos administrativos, Madrid, Instituto de Estudios Administra. tivos, 1972.

(30) Advierte, a este respecto, BaENa DEL AlCAZAR, que ala modificación de la fórmula relativa a la competencia generaliza el supuesto de la Ley de Procedimiento, ya que no se trata aquí de incompetencia del órgano, sino de incompetencia en general, siempre que dicha incompetencia sea «notoria». Es evidente que la apreciación de esta notoriedad es algo perfectamente subjetivo, que quedará a la decisión de las autoridades colegiales y de la Administración central, competentes para acordar la suspensión por causa de nulidad. Pero es más grave aún de cara a la suspensión considerar nulos de pleno derecho los actos manifiestamente contrarios a la Ley, no sólo porque el carácter amanifiestamente ilegal es algo igualmente subjetivo, sino porque supone considerar nulos actos que en el caso de la Administración central son simplemente anulables. La cuestión es meridiana, ya que la fórmula está tomada de la regulación del artículo 110 de la Ley de Procedimiento, respecto a los actos anulables que, sin embargo, pueden ser revisados de oficio mediando los requisitos procedimentales establecidos». (Estudio citado en nota $5, R A P$, núm. 74, pág. 85). 


\section{IMPUGNACIÓN EN EL ÁMBITO CORPORATIVO}

La LCP de 13 de febrero de 1974 establece, como advierte BAENA DEL Alcázar (31), la importante innovación respecto del Derecho anterior, de suprimir por completo la posibilidad de que la Administración del Estado revise los actos de los Colegios profesionales en vía de recurso, pues todos los recursos distintos del contencioso se interpondrán ahora en el seno de la correspondiente organización colegial, aunque se mantiene la dispersión anterior al establecerse que la impugnación de los actos colegiales será objeto de regulación en los Estatutos generales y que los Consejos Generales de los Colegios tendrán, entre otras funciones, la de resolver los recursos que se interpongan contra los actos de los Colegios (artículo 9, núm. 1, apartado e) (32).

Así, según los Estatutos generales de los Colegios de Arquitectectos, aprobados por Decreto de 13 de junio de 1931, contra todo acuerdo adoptado por los Colegios o sus organismos, podrán los colegiales interponer recurso ante el Tribunal profesional, y en última instancia, ante el Consejo Superior de los Colegios, salvo los casos previstos en el Decreto de creación de los mismos o en este Estatuto (artículo 7), señalándose como competencia del Consejo Superior de Colegios de Arquitectos la de resolver los recursos de alzada que los Arquitectos le eleven contra acuerdos adoptados por las Juntas de Gobierno de su Colegio (artículo 42, núm. $3 .^{\circ}$ ), acuerdos de las Juntas de Gobierno de los Colegios de Arquitectos entre los que se enumeran específicamente los de intervenir para su validez la documentación de los proyectos y direcciones de obras que hayan de tener curso administrativo por medio del sello del Colegio y visar de igual modo todos los informes de carácter privado, periciales, valoraciones, etc., los cuales deberán quedar registrados en el Colegio (artículo 19, $1^{\circ}$, d).

En cuanto a los proyectos técnicos firmados por Ingenieros de Caminos cuyo visado se deniegue, el artículo 70 del Reglamento

(31) Estudio citado, RAP, núm. 74, págs. 95 y 96.

(32) Advierte por ello BaENa que nada se opone a que se establezca una regulación de estos recursos en vía corporativa» que, aparte de diferente de uno a otro caso, no sea idéntica, ni paralela, ni análoga a la de la Ley de Procedimiento. No sólo la doble alzada, sino los recursos de súplica y queja y cualesquiera otros pueden ser reconocidos en los respectivos Estatutos. (Est. cit., $R A P$, núm. 74, pág. 96.) 
de 21 de mayo de 1959 previene expresamente que contra los acuerdos denegatorios (que corresponde resolver al Pleno de la Comisión de Inspección) los colegiados podrán recurrir ante el Consejo de Administración del Colegio en un plazo de quince días, a partir de la fecha de notificación del acuerdo (artículo 70, párrafo 3).

En el caso de proyectos firmados por Ingenieros Agrónomos, el artículo 19 del Estatuto de 16 de octubre de 1968 establece que los colegiados podrán interponer ante el Presidente del Consejo Superior de Colegios o ante el Ministro de Agricultura, según corresponda, los recursos que autorizan los presentes Estatutos.

En el caso de que en los Estatutos generales de la respectiva organización colegial no se establezca ningún régimen específico de recursos en el ámbito corporativo, será preceptivo, a nuestro modo de ver, el recurso de reposición ante el propio órgano colegial que haya denegado el visado, para poder interponer después frente a este acto recurso contencioso-administrativo conforme a la Ley reguladora de 27 de diciembre de 1956 (artículo 52). En otro caso, esto es, cuando conforme a los Estatutos generales se haya interpuesto recurso administrativo "corporativo», no será preceptivo interponer el citado recurso de reposición previo al contencioso (artículo 53-a, de la citada Ley Jurisdiccional).

Ahora bien, ni que decir tiene que no es sólo el profesional colegiado, Arquitecto o Ingeniero, autor del proyecto técnico cuyo visado haya sido denegado, quien resulta afectado en sus derechos o intereses por el acto colegial desestimatorio, ya que este acto también afecta, en definitiva, al cliente que ha encargado la redacción del proyecto. Se plantea por ello el problema de si este último está legitimado para impugnar el acto denegatorio del visado ante el correspondiente órgano colegial.

A nuestro modo de ver, aunque la LCP no hace la más mínima referencia a los clientes, habrá que estar, conforme a ella (artículo 6 , 3. $\mathrm{h}$ ), a lo que se haya previsto en los Estatutos generales, $\mathrm{y}$, en consecuencia, si en éstos se limita el régimen de impugnación solamente a los colegiados (como ocurre, por ejemplo, en los supuestos examinados de los Colegios de Arquitectos, de Ingenieros de Caminos y de Ingenieros Agrónomos), el cliente no estará legitimado para ejercer este tipo de recursos administrativos estatutarios, aunque sí, en cualquier caso, para interponer el recurso de 
reposición como trámite previo al contencioso-administrativo conforme a la citada Ley de 1956.

Esta diversidad de regímenes de impugnación frente al acto colegial que desestime el otorgamiento del visado no es sino una consecuencia más, según lo expuesto, de la dispersión que, frente al criterio unitario que informa nuestras leyes generales de procedimiento administrativo, consagra la citada Ley de Colegios Profesionales. Ahora bien, aunque esta Ley no se refiera a los clientes y las normas estatutarias de los Colegios, a que se ha hecho referencia, limiten a los colegiados la legitimación para interponer recursos contra el acto denegatorio del visado (33), es obvio que el cliente es titular de un interés legítimo, personal y directo que asimismo le legitima para impugnar tal acto en vía administrativa, mediante recurso de reposición ante el mismo órgano colegial de que proceda el acto, conforme a lo que previene la Ley reguladora de la Jurisdicción contencioso-administrativa.

\section{IMPUGNACIÓN EN VIA CONTENCIOSO-ADMINISTRATIVA}

El artículo 37, número 2, de la citada Ley Jurisdiccional de 1956 dice, como norma general, que los actos de las Corporaciones e Instituciones a que se refiere el artículo $10^{\circ}$, párrafo 2 , apartado c), podrán ser objeto directamente del recurso contencioso-administrativo, salvo que, de modo expreso, fueran susceptibles de recurso en vía administrativa ante cualquier otro organismo o entidad.

Habrá que estar, pues, según lo expuesto, a los Estatutos generales de cada Colegio (artículo 6, núm. 3-h, LCP), ya que sólo será admisible recurso de alzada cuando venga establecido en el régimen estatutario por el que se rija el Colegio correspondiente (34).

(33) Limitación cuya vigencia actual puede ponerse en duda, ya que según la LCP (art. 8, núm. 2) ala legitimación activa en los recursos corporativos y contencioso-administrativos se regulará por lo dispuesto en la Ley de esta jurisdicción y, en todo caso, estará también legitimada la Administración del Estados. No obstante, según consideramos en el texto, como en cualquier caso el cliente está legitimado para interponer recurso de reposición previo al contencioso-administrativo ante el propio Colegio que haya denegado el visado, entendemos que queda debidamente garantizado con ello desde el punto de vista jurídico, con la ventaja, además, de evitar seguir el sistema de recursos corporativos, variable según la organización colegial, costoso y más o menos complicado según el Colegio profesional de que se trate, cuya aplicabilidad entendemos referida sólo, en principio, según determinen los respectivos Estatutos generales, a los colegiados, cuando sean éstos quienes actúen por si en via administrativa.

(34) La revisión de actos en vía de recurso es una de las funciones enumeradas entre las propias del Consejo General (art. 9-1e, LCP), que, puesta en relación con 
En otro caso, como queda indicado, deberá tenerse en cuenta que, con carácter general, será necesario el recurso de reposición previo al contencioso-administrativo, por exigencia del artículo 52 de le Ley de 1956 (35).

En caso de que la sentencia que se dicte en vía contencioso-administrativa sea desestimatoria del recurso y en consecuencia confirmatoria del acto denegatorio del visado, no se plantean en principio especiales problemas. La consecuencia obvia será que el interesado, técnico o cliente, no podrá realizar la obra o instalación según el proyecto denegado, al no poder obtener conforme al mismo la preceptiva licencia en la instancia administrativa municipal. Ello, obviamente, obligará a llevar a cabo la modificación del proyecto rechazado o la elaboración de otro nuevo que no incurra en infracción grave del ordenamiento urbanístico aplicable, a fin de someterlo de nuevo a visado del correspondiente Colegio profesional.

En otro caso, cuando la sentencia contencioso-administrativa sea desestimatoria del recurso, por considerarse que la denegación del visado incurre en nulidad de pleno derecho o en cualquier forma de infracción del ordenamiento jurídico que constituya vicio de anulabilidad, $y$ en consecuencia declare la nulidad o anule el acto denegatorio de dicho visado, se producirán los efectos generales que previene la citada Ley Jurisdiccional (36), y en consecuencia el correspondiente Colegio profesional, en ejecución de la sentencia, vendrá obligado a otorgar aquél.

el precepto del artículo 8 sobre los recursos acorporativos», significa que los actos de la Junta de Gobierno del Consejo General agotan la vía "corporativa», siendo el punto máximo de la cúspide que puedan montar en la materia las normas estatutarias. (BAENA DEL ALCAZAR, est. cit., RAP, núm. 74, pág. 102.)

(35) J. Trujillo, C. Quintana y J. A. Bolea: Comentarios a la ley de lo Contencioso-administrativo, Madrid, Santillana, 1965 (tomo I, págs. 558-559). En el mismo sentido, A. Guarta: "Organismos autónomos y recursos de alzada", en Documentación Administrativa, núm. 104, págs. 23 y ss. Advierte este último autor que el artículo 37 de la Ley de lo Contencioso-administrativo se refiere al recurso de alzada y no al de reposición, pues habla de «recurso en vía administrativa ante cualquier otro organismo o entidad», y como se sabe, el recurso de reposición se presenta ante el mismo órgano que hubiere de resolverlo, según el artículo 52 de dicha Ley (pág. 26). Al decir el artículo 37-2 de la Ley citada que determinados actos podrán impugnarse directamente en vía contenciosa -dice después GUAITAno quiere significar que no se exija antes la reposición, pues luego se exige como regla general en el artículo 52 (pág. 28).

(36) Cfr. arts. 83 y 84 de la Ley reguladora de la Jurisdicción Contenciosoadministrativa. Vid. asimismo, en general, Trujillo, Quintana y Bolea, ob. cit. en nota anterior, tomo II, págs. 473 y ss. J. González Pérez: Derecho Procesal Administrativo, II. 